\title{
Innovation networks on Mediterranean Non Wood Forest Products
}

\section{Sven Mutke $^{1 *}$ (iD, Jose Antonio Bonet ${ }^{2}$ iD, Nuno Calado ${ }^{3}$ iD, Javier Calvo ${ }^{4}$ iD, Ibtissem Taghouti ${ }^{5}$ iD Concha Redondo ${ }^{4}$ iD, Inazio Martinez de Arano ${ }^{6}$ iD}

I*INIA, Forest Research Centre / iuFOR UVa-INIA, 28040 Madrid, SPAIN

${ }^{2}$ CTFC, Forest Science Technology Centre of Catalonia, 25280 Solsona, SPAIN

${ }^{3}$ UNAC, Mediterranean Forest Union, 2140-098 Chamusca, PORTUGAL

${ }^{4}$ CESEFOR, Forest Service and Promotion Centre, 40005 Soria, SPAIN

${ }^{5}$ INRGREF, National Institute for Agriculture, Water and Forest Research, 20810 Ariana, TUNISIA

${ }^{6}$ EFI, European Forest Institute, 80100 Joensuu, FINLAND

\begin{abstract}
Cite this paper as:
Mutke, S., Bonet, J.A., Calado, N., Calvo, J., Taghouti, I., Redondo, C., Martinez de Arano, I, (2019). Innovation networks on Mediterranean Non Wood Forest Products. Journal of Innovative Science and Engineering. 3(1): 1-10
\end{abstract}

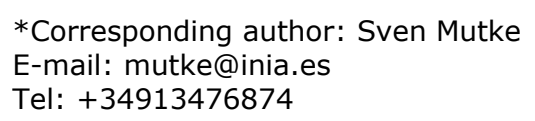

\section{(c) (i) (8)}

The works published in Journal of Innovative Science and Engineering (JISE) are licensed under a Creative Commons Attribution-NonCommercial 4.0 International License.

\begin{abstract}
Non Wood Forest Products (NWFPs) are important resources for rural economies. Highly regarded food products are collected from Mediterranean forests, such as nuts, berries, mushrooms and truffles, as well as aromatic and medicinal plants. Other NWFPs, such as resin or cork, can play a role in the circular bio-economy, providing sustainable alternatives to fossil-based raw materials. However, achieving fair levels of profitability for all actors throughout the value chain is still a challenge. Existing hourglass-shaped monopsony structures need to be resolved and market access to local producers must be strengthened. Furthermore, it is important to promote greater consumer awareness and willingness to pay for the sustainable, 'wild-collected' nature of these goods. The European thematic network INCREDIBLE (Innovation networks on Non-Wood Forest Products in the Mediterranean basin) brings together the main actors associated with NWFP with the aim of sharing knowledge, expertise and experience. Sharing information helps to identify the challenges and requirements of each NWFP value chain so that profitability and sustainability can be improved. The objective of Open Innovation is to bring together innovative ideas of actors from different organisations, thus making the best use of their respective areas of competence in order to create an effective innovation ecosystem. INCREDIBLE facilitates open innovation by establishing and operating Innovation Networks (iNets) for different NWFPs. The social, technological and silvicultural challenges and requirements for innovation in each iNet are identified and different approaches to addressing these are explored by the various actors involved in accordance with their areas of competence.
\end{abstract}

Keywords: Mediterranean NWFPs, Open innovation, Value chain development. 


\section{Introduction}

Non-Wood Forest Products (NWFPs) are defined by FAO as "products of biological origin, other than wood, derived from forests, other wooded land and trees outside forests" [1]. Throughout history, forests have constituted valuable, complex adaptative systems which provide human society with many essential goods such as timber, fibres, fuel, food, fodder, pharmaceutical products etc.). Forests also supply regulatory, supportive and cultural ecosystem services, contributing to local livelihood and providing a source of income from trade, or more recently from tourism. In most cultures, forest land has historically been considered 'commons' or crown/state territory rather than private, given their multiple uses and the multiple stakeholder groups which benefit from them. Only in recent times, with the development of rationalistic silviculture, has the function of forests been limited to the provision of wood, often considered the only important management objective. In other words, the science-based optimisation of revenue from timber for the forest owner often neglected or even prohibited the collection and/or use of most other forest resources and services such as livestock grazing or gathering of firewood for local household use [2], [3]. This limited, 'timber-alone' perspective often led to short-sighted exploitation of wood resources, to the detriment and even destruction of the rest of the forest ecosystems in Europe and its colonies. However, it is now acknowledged that this approach to forest management does not address the challenges currently faced by forests and those who depend on them [1].

At least in the tropics, NWFPs regained prominence following decolonisation thanks to the recognition of these products as being essential to the livelihood of such areas and the importance of sustainability in forest use. Moreover, they can provide food security and contribute to rural household economies as well as national economies while at the same time aiding these areas to achieve environmental objectives. Despite this resurgence of NWFPs in the tropics, European forest policies and management continued to limit the concept of forestry to a mere wood and pulp supply chain, neglecting the fact that European forests produce other goods that could provide economic benefits. In Mediterranean countries in particular, NWFPs can contribute significantly to rural economies. The latest report on the state of European forests estimates the total value of NWFPs in Europe (83\% of which is generated by plant products) at 2.27 billion euros (G€), more than $10 \%$ the amount associated with round wood (18 G€) [4]. Highly regarded food products are collected from Mediterranean forests, such as nuts, berries, mushrooms and truffles, as well as aromatic and medicinal plants. Other NWFPs such as resin or cork play a role in the circular bio-economy as renewable alternatives to fossil-based raw materials. For instance, in cork-producing countries such as Portugal or the Maghreb, revenue from NWFPs exceeds that from round wood [5], [6]. Applying a different calculation approach, the FAO estimated the value of NWFP removals in Europe at $7.7 \mathrm{G} €$ annually, which is $37 \%$ the amount associated with round wood (20.7 G€) [7]. More importantly, the EU28 export over $€ 2$ billion worth of NWFP annually and import over $€ 3$ billion, with a clear net deficit in internal supply [5]. The economic importance of other ecosystem services, apart from sourcing of raw materials (i.e. support and regulation services) are beyond the scope of this paper, as are any cultural, spiritual or health related benefits of forests and therefore will not be discussed further. However, it should be noted that NWFPs themselves are closely linked to conservation issues, traditional knowledge, territorial identity, recreation, gastronomy and other cultural values.

In the Mediterranean region, wood growth is low, timber value chains are weak and a wide range of NWFPs account for a considerable share of total forest production. They play an important role in sustainable forest management, wildfire 
prevention and rural economies. The inclusion of NWFPs as part of innovative multi-purpose forest management is therefore a fundamental element in the development of an alternative to traditional 'wood-alone' forestry. This multifunctional or ecosystem-based approach relies on the wide array of products and ecosystem services that Mediterranean forests provide. Recent research points to the far-reaching impacts of NWFPs on the rural-urban relationship. According to a survey of 15,000 European households, over 90\% of them were aware of consuming NWFPs, while $25 \%$ had actually picked or harvested NWFPs themselves from forests during the previous year. This sociocultural potential of NWFPs could be capitalised on as part of territorial marketing and rural tourism strategies [8], [9].

Hence, if used wisely, NWFPs can make a very significant contribution to an effective, inclusive bio-based economy and therefore in turn to rural development. In this respect, the current and potential contribution of NWFPs to the economy and rural development in North African Mediterranean countries is even higher [6]. Bearing in mind the high rate of unemployment amongst the young rural population, there are significant opportunities to be exploited as European markets are eager not only for quality NWFP-based products but also for the, as yet incipient, 'green tourism' offer.

However, achieving fair levels of profitability for all actors throughout the value chain continues to be a challenge. Occupational health and safety for collectors can be improved through technological innovation. In order to resolve hourglass-shaped monopsony structures, the central players of which are often located away from the primary production forest communities, regions or even countries, direct global market access to local producers must be strengthened, and consumer awareness must be improved, promoting willingness to pay for the fair, sustainable, 'wild-collected' nature of these goods. In this regard, internet and ICT can certainly provide new tools and business opportunities.

\section{Material and Methods}

In the context described above, the Mediterranean Facility of the European Forest Institute (EFIMED) has launched a thematic network on Mediterranean Non-Wood Forest Products, funded by the European Union's Horizon 2020 Research and innovation programme [10]. The acronym INCREDIBLE stands for: "Innovation Networks of Cork, Resins and Edibles in the Mediterranean basin". Focusing on innovation and capacity building in production, processing and trade of Mediterranean NWFPs, INCREDIBLE aims not only to improve two-way channels linking science and practice (the classic top-down innovation paradigm), but also to facilitate open innovation, based on a network of actors from different organisations and regions in order to pool innovative ideas, making the best use of each of their areas of competence and creating an effective innovation ecosystem. As with traditional family-based agriculture, the many thousands of small private forest estates, NFWP collectors, and primary NWFP-processing SMEs can benefit from economy of scale and increase capacity by networking with each other. Additionally, the current lack of effective lobbies at national and European scale is holding back the removal of institutional and regulatory restrictions and dysfunctionalities, even in cases where the latter are obvious. 
To achieve these goals, INCREDIBLE has established Innovation Networks (iNets) for five different NWFP types, namely cork, resin, mushrooms \& truffles, wild nuts \& berries, and aromatic \& medicinal plants. These iNets bring together relevant actors with complementary knowledge, expertise and experience from the seven participating Mediterranean countries, although they are open to stakeholders from across the Mediterranean, including non-EU countries, which are able to participate via web contact [12].

In 2018, each iNet held an international Scoping Seminar with participating stakeholders to identify and validate the most important social, technological and silvicultural challenges for each NWFP value chain. Different ways to address the requirements for innovation to improve profitability and sustainability were explored, with all actors contributing in accordance with their respective areas of competence. The Scoping Seminars brought together more than 180 stakeholders from NWFPs value chains, research and policy making, in order to share and exchange knowledge and expertise, promoting cross-sectoral collaboration and highlighting the value and potential of NWFPs in the region. The seminars set priority issues and addressed knowledge gaps for each iNet identified by participants, including forest owners, collectors, entrepreneurs, researchers, policy makers, industry representatives and public managers. A valuechain mapping exercise formed an integral part of each meeting and led to a common roadmap for innovation and collaboration in each of the five iNets [13].

\section{Results}

\subsection{Cork iNet priority themes to focus INCREDIBLE actions}

The Cork iNet scoping seminar took place in July in Sardinia, Italy. 27 participants attended the seminar, representing the most significant links of the cork value chain; namely forest owners, cork industry, research and development, wine industry, national and regional governments and chamber of commerce.

Most of the participants were from Italy, though some participants came from Portugal, Spain and Tunisia. A very interesting and participative discussion allowed questions to be addressed and knowledge to be shared among the different players and countries represented. The interactive discussions, exercises, group workshops and session dynamics all contributed substantially to the identification of priority themes to be focused on in future INCREDIBLE activities related to the cork value chain:

1. Climate change adaptation and cork oak decline.

2. Evaluation of Ecosystem services (life cycle approach).

3. Profitability of the value chain.

4. Policies targeted on multifunctional ecosystem management.

5. Communication to raise consumer awareness, prioritise research, etc., compare several examples of different regulation approaches among the different countries and certain crucial policy innovation ideas such as:

- Implementation of effective regulations to minimize the grey economy;

- Establishment of payment for ecosystem services (PES) models; 
- Maintenance/development of regulations to assure the sustainability of the cork oak ecosystem, in particular with regard to land use for pasture and cattle grazing, which jeopardises appropriate regeneration of over-mature oak forests and woodlands.

Other issues discussed during the meeting were cork quality and improved understanding of the relationship between cork taint causing fungal metabolite TCA (2,4,6,-trichloroanisole) and forest management models, as well as the effects of pests, diseases and extreme drought events on cork yield quantity and quality.

\subsection{Resin iNet priority themes to focus INCREDIBLE actions}

The Resins iNet scoping seminar was held in May in Valladolid, Spain. The 38 participants came from Spain, France and Portugal, the three countries that have historically been the main resin producers in Europe.

As regards sectorial representation, all the links in the natural resin value chain were represented, with the exception of consumers. Activities aimed at evaluating expectations, reviewing the value chain along with the generation of a SWOT diagram (strengths, weaknesses, opportunities, threads) served to provide sector self-recognition while also reflecting on the problems and deficiencies that can be covered by R\&D initiatives. Future INCREDIBLE events aim to improve this sectoral cohesion, identified as an essential objective when creating the innovation network.

Participants showed particular interest in joint resolution of the challenges facing the sector, evidenced by the volume and quality of observations and ideas. In the workshop sessions in which the representatives of the different links of the value chain interacted, there was a notable desire to work towards greater complementarity and seek points of agreement.

A large number of innovation priorities were put on the table, four of which were finally chosen as the most important:

1. Resin yield modelling in a context of climate change.

2. Compatibility of resin harvesting with other forest uses and services.

3. Improvement of the working conditions of resin tappers.

4. Development of new natural resin derivative products and markets.

Further necessities were highlighted, such as the extension of sustainable forest management certification schemes, from forest through extraction to the processing facilities, and by chains of custody up to the final markets. The need for training of technicians and forest managers was also identified.

\subsection{Aromatic \& medicinal plant (AMPs) iNet priority themes to focus INCREDIBLE actions}

The AMPs iNet scooping seminar was held in June in Tunisia with the participation of 42 stakeholders from Tunisia, Greece, Spain, Portugal and France. All actors in the AMPs value chain were represented in the seminar: producers, government agencies, researchers, NGOs and exporters.

The seminar began with presentations of the current situation of the AMP sector in Tunisia, Spain and Greece, which opened the debate on an inspiring note. Various activities (SWOT analysis, value chain mapping...) were used provide 
improved characterisation of actors and fluxes in the value chain and to prioritize key themes to focus INCREDIBLE actions.

Four key issues were identified by the end of the seminar:

1. Support of production and marketing capacities.

2. Natural Resource Management and biodiversity conservation.

3. Legal framework adjustment.

4. Certification and traceability.

Given that aromatic and medicinal plant collectors, or growers, are often local self-employed workers, cooperatives, or agricultural development groups, and that they often carry out the initial processing or drying prior to selling their production to large firms, they are considered the main supply chain link to be actively involved. Moreover, they should be skilled and aware of biodiversity conservation, using practices aimed at conservation.

The AMP value chain is characterized by the commonly informal nature of its base (collectors without formal permits), which leads to a value chain with little vertical integration and hardly any horizontal collaboration. Collectors have limited access to end market information and obtain low profits in comparison with other actors. In addition, the collectors are the least integrated in the value chain. Interaction between researchers (academic sector) and processors in order to evaluate research output is almost non-existent.

\subsection{Mushroom \& truffle iNet priority themes to focus INCREDIBLE actions}

The seminar scoping the Mushroom \& truffle iNet activities was held in June in Spain, with 56 attendees, from Spain, France, Italy, Croatia, and Greece. The iNet of mushrooms and truffles is devoted to two fungal non-wood forest product types that share several similarities, as well as unique qualities and challenges. Therefore, the Scoping Seminar was organized in two different sessions, one devoted to wild-collected mushrooms and the second focused on the truffle sector. Documents previously prepared by INCREDIBLE partners, including value chain mapping and a SWOT analysis, were discussed in depth and new insights were identified and added to the final documents.

Despite differing concerns among participants from the different countries, and even within regions in the same country, the participants agreed on the identification of challenges as well as priority issues to enhance the wild mushroom and truffle sector. The main challenges identified by the interregional workshops were:

1. Marketing.

2. Management of truffle plantations and development of myco-silviculture.

3. Regulation and taxation systems and training.

The priority issues identified by those attending the Scoping Seminar with regard to addressing these legal, social, research, or communication challenges were: regulation of wild mushroom picking; appropriate taxation for mushroom picking activity; control of illegal harvesting/informal markets; domestication of wild mushroom species; increase in 
mushroom yields through defined myco-silviculture; certification for black truffle traceability, quality standards, and labels. A recurrent topic was myco-tourism, the local and regional weekend tourism of urban population associated with recreational mushroom hunting.

\subsection{Wild nuts \& berries iNet priority themes to focus INCREDIBLE actions}

Twenty participants of the scoping seminar held in June in Portugal were Portuguese stakeholders, along with a few attendees from Spain and France. The main focus was on several serious problems that both the chestnut and Mediterranean pine nut sectors are currently facing, including severe damage by pests and diseases, especially two exotic pests which have recently arrived in the region: the chestnut gall wasp and the western conifer seed bug. Yields have also been diminishing recently due to increasing droughts. Furthermore, what was once loosely termed the "informal supply chain" is nowadays clearly understood to be theft from the legal landowners. This practice is supported by demand from persisting black markets, forming a parallel complete supply chain which is both tax-free and lacking any product guarantee, often for exportation. These problems are also the result of the continuing lack of effective implementation of certified, traceable quality standards "from forest to fork", despite mandatory traceability for European food being introduced in Regulation (EC) 178/2002 on food safety.

The following priority issues were earmarked for future iNet activities:

1. Processing quality (standards and good practice for each product line).

2. Mitigation of damage by pest and diseases, as well as that resulting from climate change.

3. Optimised forest and plantation management and tending schemes (good practice).

4. Possibilities for new chestnut-based products.

5. Improved marketing, labelling, and improved consumer awareness rise with regard to the health, environmental and cultural benefits of wild nut consumption, e.g. labelling of organic food and/or sustainably managed forest product.

The main priority is the need to recover sustained and sufficient levels of production following the collapse in supply over recent years while advancing towards the deployment of improved, adapted genetic material, more widespread use of optimized management techniques, and the development of integrated pest management systems. However, measures are also required to avoid theft and tackle the black market, possibly accompanied by the development and wider use of protocols, standards or guarantee labels aimed at traceability, processing standards and product quality. In this case, INCREDIBLE could play a role in unifying the requests of the different actors in the value chain to public authorities, in conjunction with existing networks such as Eurochestnut or Operative Groups.

Thus, the initial objective could be as simple as achieving increased consumer (and public authority) awareness with regard to the differences between genuine Mediterranean pine nuts from Pinus pinea and other, less-esteemed pine seeds from completely different Asiatic pine species (P. koraiensis, P. gerardiana, etc.), the labelling of which in retail outlets does not differentiate between such products despite substantial differences. Similarly, the consumer is often insufficiently informed as to the difference between the true black truffle Tuber melanosporum and the lesser regarded Tuber indicum imported from China. 


\section{Discussions}

The reports from each Scoping seminar provide concise descriptions of the situation in the field and therefore are a good starting point for future regional workshops and international meetings [13]. Despite the wide range of NWFPs types and regional differences, several common issues can be identified. Climate change is one of the major threats to Mediterranean forest ecosystems and ecosystem services, including provision of wood and non-wood forest products. While agriculture increasingly relies on irrigation, wild-collected products are completely dependent on natural climate conditions. Under the current scenario of climate change, this situation implies increasing recurrence of crop failure or reduced quantities. Vitality of forest ecosystems is further threatened by incidence of pests and diseases, some of which have been inadvertently introduced through global trade. While the impact of some of these is to reduce the output of forest products, others jeopardising the very existence of some forest species or ecosystems. Consecutive crop failures due to drought or pests can lead to the economic collapse of entire value chains. Collection of each product involves different challenges, ranging from lack of skilled pickers and vocational training, inadequate leasing, tax and labour regimes, inappropriate harvesting practices, lack of technical innovation or its implantation, to the lack of social recognition of collectors' guilds as a vocation.

Communication is another important challenge to be addressed. Communication on the one hand across the value chain between forest owners or growers, collectors, traders, processors, secondary industries, and consumers in order to achieve better value chain integration. On the other hand, communication with other actors such as public authorities, the research community, or international agencies. Communication problems include the reported lack of knowledge transfer and capacity building, as well as insufficient media coverage and publicity for NWFPs.

Even lack of traceability can be included as communication failure, in other words, not being capable of transmitting the true values of identity, quality, legality and fair trade of the wild collected products to the end users. This situation will not improve as long as NWFPs continue to be considered 'bulk commodities' on the markets rather than wildcollected natural products of special value. The problem is compounded by the fact that growers or collectors often sell locally to intermediate agents who take the products to the markets without due identification of the source of the products. To overcome hourglass-shaped monopsony structures, often located away from the primary production forest communities, regions or even countries, direct global market access to local producers must be strengthened, and consumer awareness increased with regard to the fair, sustainable, wild-collected origin of the products.

Consequently, improved dissemination of information about standards, quality control, and certification methods is needed both for harvesting (collection) and processing. Existing examples of good practices should be passed on among stakeholders throughout the value chain, as well as among regions and countries. Cross-fertilisation among product types may be fruitful.

Inappropriate, confusing, scarce or non-existent regulation for collecting, trading, producing and marketing of NWFPs is a critical issue that has arisen across most iNets. Some Mediterranean countries have existing regulation for some NWFPs, but in other countries this is not the case. Moreover, the amount of research into NWFPs varies widely between 
Mediterranean countries, often as a consequence of differing degrees of interest from political and governmental structures.

Lack of regulation and control often provides a perfect opportunity for black markets, inherited from former "informal" supply chains, but scaled up to international connections. These black markets can be of particular relevance in the case of high-value products such as wild nuts, mushrooms and truffles. Truffles, which are one of the most valuable NWFP, are often traded 'under the table' and smuggled between countries. Again, traceability of foodstuff "from farm [here: forest] to fork" has been mandatory in Europe since Regulation (EC) 178/2002, which laid down procedures regarding food security. Illegal activity such as unauthorised harvesting and undeclared trade result in significant losses to sectorial economies as well as tax revenues. They can affect consumer health and rights and contribute to the invisibility of NWFPs' in statistics, politics and ultimately, in the consciousness of society.

The situation described above is in stark contrast with the positive association of the majority of non-wood products with cultural heritage, traditional multifunctional forest management, gourmet food or health. Bearing this in mind, appropriate management of the various aspects of growing non-wood forest products is of common interest and requires active involvement of governmental agencies in order to manage the communication between the different actors in the value chain as well as to develop and adapt policy, regulate the market and create incentives, etc. [13]. The road map for the iNet activities is based on the results from the Scoping Seminars and is available via the INCREDIBLE website [11].

\section{Conclusion}

The initial stages of the work undertaken as part of the European INCREDIBLE project confirms what the FAO highlighted twenty years ago in the case of the Mediterranean, namely, the extensive efforts required to develop the full potential of NWFPs [1]. Forest policies and management need to be adapted to ensure the potential of non-wood forest resources and products. Increased research and communication as regards biology, ecology and uses of non-wood forest resources are essential to achieve accurate assessment, sustainable management and a fair value chain. It is particularly important to identify ways to improve the employment and income-generating potential of NWFPs through open innovation in harvesting, storage, transport, processing, manufacturing and marketing.

\section{Acknowledgments}

This paper about the European Thematic Network INCREdible is based on a communication to the $4^{\text {th }}$ International Non Wood Forest Product Symposium, Bursa, October 2018. This project has received funding from the European Union's Horizon 2020 research and innovation programme under grant agreement $\mathrm{N}^{\mathrm{o}} 774632$.

\section{References}

[1] FAO (1999). Towards a harmonized definition of non-wood forest products, Unasylva 50(198). Food and Agriculture Organization of the United Nations, Rome. 
[2] Marx, K. (1976). Debatten über das Holzdiebstahlsgesetz, Rheinische Zeitung, 1842. Werke, Band 1, Karl Marx, and Friedrich Engels, pp. 109-147. Dietz Verlag, Berlin. ISBN 978-3-320-02088-0.

[3] Bathe, G. (2018). Ancient Rights in Ancient Forests (Chapter 4). Ancient Woodlands and Trees: A Guide for Landscape Planners and Forest Managers, Alper H. Çolak, Simay Kurca, and Ian D. Rotherham, IUFRO World Series Vol. 37. International Union of Forest Research Organizations, Vienna, pp. 64-77. ISBN 978-3-90276291-7.

[4] FOREST EUROPE (2015). State of Europe's Forests 2015. Ministerial Conference on the Protection of Forests in Europe. FOREST EUROPE Liaison Unit Madrid, 312 p.

[5] Wong, J.L.G. and Prokofieva, I. (eds.) (2014). Report presenting synthesis of regional sectoral reviews to describe the State of the European NWFP. Project deliverable D1.3 StarTree project (EU project 311919), 95 $\mathrm{pp}+3$ Annexes.

[6] Daly Hassen, H. (2016). Assessment of the socio-economic value of the goods and services provided by Mediterranean forest ecosystems: critical and comparative analysis of studies conducted in Algeria, Lebanon, Morocco, Tunisia and Turkey. Plan Bleu, Valbonne: 38 p. ISBN 978-92-5-109417-4

[7] FAO (2010). Global Forest Resources Assessment 2010, Main Report. FAO Forestry Paper $n^{\circ} 164$. Food and Agriculture Organization of the United Nations, Rome, 340 p. ISBN 978-92-5-106654-6

[8] Lovrić, M., Da Re, R., Vidale E. et al. (2016). Collection and consumption of wild forest products in Europe. Wild Forest Products in Europe Conference, 13-14 October 2016, Barcelona. Book of abstracts. p. 50.

[9] Da Re. R.., Vidale, E., Corradini, G., Pettenella, D. (2015). The regional markets of NWFP: current situation and effect on SME. Project deliverable D3.2. StarTree project (EU project 311919), 227 p.

[10] CORDIS INCREdible website. https://cordis.europa.eu/project/rcn/213789_en.html [Accessed: 31 August 2018]

[11] INCREDIBLE project website.: https://incredibleforest.net/ [accessed: 31 August 2018]

[12] INCREDIBLE iNet participating form. Available: https://incredibleforest.net/content/join-inet

[13] Buršić, D., Zgrablić, Ž., Brenko, A., (2018). A Road Map for innovating NWFPs value chains. Project deliverable D1.3. INCREDIBLE project (EU project 776432), $39 \mathrm{p}$. 